\title{
EFFECTS OF HIGH SPINAL ANESTHESIA ON CEREBRAL CIRCULATION AND METABOLISM IN MAN ${ }^{1,2}$
}

\author{
By JEROME KLEINERMAN, SALVATORE M. SANCETTA, AND \\ DONALD B. HACKEL
}

\author{
(From the Department of Pathology and Medicine, Western Reserve University School of \\ Medicine at Cleveland City Hospital, Cleveland, Ohio)
}

(Submitted for publication August 1, 1957; accepted September 12, 1957)

The effects of high spinal anesthesia on the general $(1,2)$, hepatic $(3)$, and coronary (4) hemodynamics have been previously reported by our group. Because hypotension produced by high spinal anesthesia may be a potential hazard to the circulatory sufficiency of the brain, it was considered important to study the effects of high spinal anesthesia on the cerebral circulation and metabolism.

Studies by others have been concerned with the effects of differential spinal block on the cerebral circulation of hypertensive individuals (5) and the effect of hypotensive drugs on the cerebral circulation of aged persons (6) and hypertensives (7). The majority of patients in this study are normotensive, but the effects of high spinal anesthesia on a small group of hypertensives is included. The anesthetic level is higher and the amount of spinal anesthetic agent employed is larger than in studies reported by others, simulating the dosage used in producing surgical high spinal anesthesia, although surgical procedures were not undertaken in these subjects.

\section{MATERIAL AND METHODS}

Nineteen patients were selected from the medical wards. Of these, 15 were normotensive and free of cardiopulmonary disease, and 4 were hypertensive. Following an overnight fast and morning sedation (pentobarbital sodium, $0.1 \mathrm{Gm}$.) the patients were transported to the cardiovascular laboratory, where the ambient temperature was maintained between 23 and $24^{\circ} \mathrm{C}$. In some instances a No. 6-8 F Goodale birds-eye catheter was introduced via a medial arm vein into the jugular bulb and the position of the tip checked repeatedly by fluoroscopic examination. In other instances direct puncture of the jugular

1 This work was done in part during the tenure of a Research Fellowship of the American Heart Association (Jerome Kleinerman and Donald B. Hackel).

2 Supported in part by Research Grants Nos. H-1382 and $\mathrm{H}-863$ from the National Heart Institute of the United States Public Health Service. bulb was employed. Blood samples were then drawn for basal determination of cerebral blood flow, arterial and jugular venous blood gases, $\mathrm{pH}$, glucose, lactate, and pyruvate. Following the basal determinations, one group of 13 patients (age range, 22 to 60 ; average, 41.6 years) was given a spinal anesthetic of 150 to $200 \mathrm{mg}$. of procaine by barbotage. In all instances the arbitrary criteria previously described for high spinal anesthesia $(1,2)$ were met and confirmed by plethysmographic (8) demonstration of increased finger blood flow. Thirty minutes after the administration of the anesthetic all studies were repeated. A second group of six patients (age range, 44 to 66 ; average, 56 years) served as "double controls." Thirty minutes after the initial basal study a second set of determinations was performed without the administration of the anesthetic. In all instances patients were maintained in total head-down body tilt of 5 degrees. Vasopressor drugs were not given at any time.

Blood oxygen contents, carbon dioxide contents and $\mathrm{pH}$ determinations were performed in duplicate, and checks required to 0.2 volume per cent for oxygen and $\mathrm{CO}_{2}$ and to $0.01 \mathrm{pH}$ unit. Jugular venous and brachial arterial oxygen contents and arterial oxygen capacity were determined spectrophotometrically according to the method of Hickam and Frayser (9) and frequently spotchecked by simultaneous gasometric analysis. Carbon dioxide content of arterial blood was determined by the manometric method of Van Slyke and Neill (10) and arterial blood $\mathrm{pH}$ readings were obtained by use of the Cambridge glass electrode potentiometer at room temperature, and corrected to body temperature (11). Values for $\mathrm{pCO}_{2}$ were obtained from the nomogram of Singer and Hastings (12). Glucose (13), lactate (14), and pyruvate (15) determinations were done in duplicate on arterial and venous blood.

Cerebral blood flow (CBF) was determined by the manometric technique of Kety and Schmidt (16) and expressed as $\mathrm{ml}$. per $100 \mathrm{Gm}$. of brain tissue per minute. Cerebral oxygen consumption $\left(\mathrm{CMR} \mathrm{O}_{2}\right)$ was calculated as the product of $\mathrm{CBF}$ and the arterial-jugular venous $\left(\mathrm{A}-\mathrm{VO}_{2}\right)$ oxygen difference. This is expressed in terms of $\mathrm{ml}$. per $100 \mathrm{Gm}$. of brain tissue per minute. Cerebral glucose consumption (CMR gl) was similarly calculated by using the arterial-jugular venous glucose $(\mathrm{A}-\mathrm{Vg} 1)$ difference and is expressed as $\mathrm{mg}$. per $100 \mathrm{Gm}$. per minute.

The brachial arterial pressure was measured through a No. 19 indwelling arterial needle, transduced via Statham strain gauges, amplified by a Brush D.C. amplifier, 
and recorded on the Brush multi-channel oscillograph. Mean arterial blood pressures (MABP) were obtained by planimetric integration of the contours recorded during two successive respiratory cycles.

Cerebrovascular resistance (CVR) was calculated by the formula

$$
\mathrm{CVR}=\frac{\text { mean arterial blood pressure }}{\text { CBF per } 100 \mathrm{Gm} \cdot \text { per minute }}
$$

and expressed as $\mathrm{mm}$. $\mathrm{Hg}$ per $\mathrm{ml}$. per $100 \mathrm{Gm}$. per minute. In calculating the mean arterial blood pressure, the readings taken prior to and immediately after the flows were averaged.

\section{RESULTS}

The data are presented in Tables I through III. The data have been treated statistically, although in the case of the hypertensives the small number of observations precluded such analysis.

\section{Mean arterial blood pressure}

The MABP in the normotensive group fell from 93 to $63 \mathrm{~mm}$. $\mathrm{Hg}$ during high spinal anesthesia. The decrease in mean blood pressure for the four hypertensives was from 158 to $79 \mathrm{~mm}$. $\mathrm{Hg}$. In the double control group the change was from 100 to $106 \mathrm{~mm}$. Hg. The marked decrease in the normotensive spinal anesthesia group is highly significant when compared to the variation in the double controls.

\section{The cerebral blood flow}

The mean CBF in the normotensive group did not change significantly during high spinal anesthesia. The prespinal value was $45 \mathrm{ml}$. per 100

TABLE I

Cerebral hemodynamics and blood gases in high spinal anesthesia*

\begin{tabular}{|c|c|c|c|c|c|c|c|c|c|c|c|c|c|c|}
\hline \multirow{3}{*}{$\begin{array}{l}\text { Patient } \\
\text { Diagnosis }\end{array}$} & \multicolumn{14}{|c|}{ Normotensives } \\
\hline & \multirow{2}{*}{\multicolumn{2}{|c|}{$\begin{array}{c}\text { F. D. } \\
\text { Chronic } \\
\text { alcoholism }\end{array}$}} & \multirow{2}{*}{\multicolumn{2}{|c|}{$\begin{array}{l}\text { J. R. } \\
\text { Pneumonia, } \\
\text { recovered }\end{array}$}} & \multicolumn{2}{|c|}{ B. M. } & \multicolumn{2}{|c|}{ C. T. } & \multicolumn{2}{|c|}{ M. L. } & \multicolumn{2}{|c|}{ S. K. } & \multicolumn{2}{|c|}{ M. B. } \\
\hline & & & & & $\begin{array}{l}\text { Pneun } \\
\text { recov }\end{array}$ & $\begin{array}{l}\text { lonia, } \\
\text { ered }\end{array}$ & $\begin{array}{l}\text { Chr } \\
\text { alcoh }\end{array}$ & $\begin{array}{l}\text { onic } \\
\text { olism }\end{array}$ & $\begin{array}{l}\text { Py } \\
\text { neph } \\
\text { reco }\end{array}$ & $\begin{array}{l}\text { lo- } \\
\text { ritis, } \\
\text { ered }\end{array}$ & $\begin{array}{l}\text { Gen } \\
\text { par } \\
\text { tre }\end{array}$ & & 1. $\underset{\begin{array}{r}\text { Barbit } \\
\text { recovic }\end{array}}{\text {. }}$ & $\begin{array}{l}\text { turate } \\
\text { ation, } \\
\text { ered }\end{array}$ \\
\hline Sex & \multicolumn{2}{|c|}{$\mathbf{M}$} & \multicolumn{2}{|c|}{$\mathbf{M}$} & \multicolumn{2}{|c|}{$\mathbf{M}$} & \multicolumn{2}{|c|}{$\mathbf{M}$} & \multicolumn{2}{|c|}{$\mathbf{F}$} & \multicolumn{2}{|c|}{$\mathbf{M}$} & \multicolumn{2}{|c|}{$\mathbf{F}$} \\
\hline Age & \multicolumn{2}{|c|}{22} & \multicolumn{2}{|c|}{38} & \multicolumn{2}{|c|}{26} & \multicolumn{2}{|c|}{60} & \multicolumn{2}{|c|}{26} & \multicolumn{2}{|c|}{42} & \multicolumn{2}{|c|}{51} \\
\hline \multirow[t]{2}{*}{ Spinal level } & \multicolumn{2}{|c|}{$T_{2}-T_{2}$} & \multicolumn{2}{|c|}{$T_{3}$} & \multicolumn{2}{|c|}{$T_{2}(R)-T_{3}(L)$} & \multicolumn{2}{|c|}{$T_{2}-T_{3}$} & \multicolumn{2}{|c|}{$T_{1}$} & \multicolumn{2}{|c|}{$T_{2}$} & \multicolumn{2}{|c|}{$T_{2}$} \\
\hline & C & $\mathbf{E}$ & C & $\mathrm{E}$ & C & $\mathrm{E}$ & C & $\mathbf{E}$ & C & E & C & $\mathbf{E}$ & C & $\mathbf{E}$ \\
\hline $\begin{array}{l}\text { Art. } \mathrm{O}_{2}, \\
\text { vol. } \%\end{array}$ & 9.6 & 10.6 & 18.5 & 18.4 & 18.9 & 19.4 & 10.6 & 10.5 & 13.1 & 12.4 & 17.2 & 16.2 & 16.0 & 16.0 \\
\hline $\begin{array}{l}\text { Jug. Ven. } \mathrm{O}_{2} \text {, } \\
\text { vol. \% }\end{array}$ & 3.1 & 4.0 & 12.7 & 12.6 & 13.7 & 12.5 & 4.9 & 3.8 & 6.8 & 6.9 & 8.4 & 8.3 & 10.2 & 10.3 \\
\hline $\begin{array}{l}\text { A-V O2, } \\
\text { vol. } \%\end{array}$ & 6.5 & 6.6 & 5.8 & 5.8 & 5.2 & 6.9 & 5.7 & 6.7 & 6.3 & 5.5 & 8.8 & 7.9 & 5.8 & 5.7 \\
\hline $\begin{array}{l}\mathrm{O}_{2} \text { Cap.; } \\
\text { vol. \% }\end{array}$ & 10.6 & 11.6 & 20.2 & 19.4 & 19.8 & 19.7 & 11.8 & 11.6 & 13.9 & 13.3 & 18.2 & 17.6 & 17.6 & 17.3 \\
\hline$\underset{\%}{\text { Art. Sat., }}$ & 91 & 91 & 92 & 95 & 96 & 99 & 90 & 90 & 94 & 93 & 95 & 93 & 91 & 91 \\
\hline $\begin{array}{l}\text { Art. } \mathrm{CO}_{2} \text {, } \\
\text { vol. } \%\end{array}$ & 39.4 & 41.9 & 47.0 & 46.4 & 46.3 & 48.0 & 45.5 & 45.3 & 40.1 & 40.2 & 39.0 & 39.7 & 44.0 & 42.4 \\
\hline Art. pH & 7.41 & 7.35 & 7.41 & 7.40 & 7.34 & 7.35 & 7.38 & 7.42 & 7.40 & 7.40 & 7.41 & 7.42 & 7.42 & 7.40 \\
\hline $\begin{array}{l}\text { Art. pCO, } \\
\text { mm. Hg }\end{array}$ & 31 & 37 & 40 & 40 & 46 & 46 & 38 & 35 & 33 & 33 & 33 & 32 & 35 & 35 \\
\hline Pulse & 75 & 60 & & & 83 & 86 & 91 & 94 & 81 & 73 & 70 & 68 & 79 & 68 \\
\hline$\underset{\text { mm. }}{\text { MABP }}$ & 92 & 62 & 92 & 66 & 100 & 66 & 99 & 59 & 69 & 55 & 98 & 61 & 86 & 72 \\
\hline$\underset{\mathrm{ml} . / 100 \mathrm{Gm} . / \mathrm{min} .}{\mathrm{CBF}}$ & 37 & 41 & 58 & 60 & 55 & 49 & 31 & 29 & 50 & 59 & 46 & 49 & 41 & 49 \\
\hline $\begin{array}{l}\mathrm{CMR}_{\mathrm{ml} . / 100} \mathrm{O}_{2} \\
\mathrm{Cm} . / \mathrm{min}\end{array}$ & 2.4 & 2.7 & 3.2 & 3.3 & 2.9 & 3.4 & 1.8 & 1.9 & 3.1 & 3.2 & 4.1 & 3.9 & 2.47 & 2.8 \\
\hline CVR & 2.4 & 1.7 & 1.7 & 1.0 & 1.8 & 1.3 & 2.9 & 2.0 & 1.4 & 0.9 & 2.1 & 1.4 & 2.1 & 1.5 \\
\hline$\underset{\mathrm{mg} . / 100 \mathrm{Gm} . / \mathrm{min} .}{\mathrm{CMR} \text {. }}$ & 6.3 & 4.1 & 3.3 & 3.4 & 1.6 & 2.9 & 2.5 & 2.0 & 3.0 & 5.9 & 4.1 & 2.9 & 5.6 & 0.6 \\
\hline
\end{tabular}

* Abbreviations: MABP $=$ mean arterial blood pressure; $\mathrm{CBF}=$ cerebral arterial blood pressure; $\mathrm{CMR}_{2} \mathrm{O}_{2}=$ cerebral oxygen consumption;

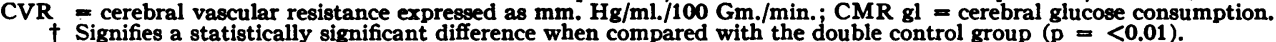


CEREBRAL HEMODYNAMICS IN HIGH SPINAL ANESTHESIA

TABLE I-Continued

Cerebral hemodynamics and blood gases in high spinal anesthesia

\begin{tabular}{|c|c|c|c|c|c|c|c|c|c|c|c|c|c|c|c|}
\hline \multicolumn{6}{|c|}{ Normotensives - continued } & \multicolumn{10}{|c|}{ Hypertensives } \\
\hline \multirow{2}{*}{\multicolumn{2}{|c|}{$\begin{array}{c}\text { M. S. } \\
\text { Pneumonia, } \\
\text { recovered }\end{array}$}} & \multirow{2}{*}{\multicolumn{2}{|c|}{$\begin{array}{c}\text { A. G. } \\
\text { Chronic } \\
\text { pancreatitis }\end{array}$}} & \multirow{2}{*}{\multicolumn{2}{|c|}{ Mean }} & \multirow{2}{*}{\multicolumn{2}{|c|}{$\begin{array}{c}\text { M. B. } \\
\text { Essential } \\
\text { hypertension }\end{array}$}} & \multirow{2}{*}{\multicolumn{2}{|c|}{$\begin{array}{c}\text { E. T. } \\
\text { Essential } \\
\text { hypertension }\end{array}$}} & \multirow{2}{*}{\multicolumn{2}{|c|}{$\begin{array}{c}\text { J. H. } \\
\text { Essential } \\
\text { hypertension }\end{array}$}} & \multirow{2}{*}{\multicolumn{2}{|c|}{$\begin{array}{c}\text { F. E. } \\
\text { Essential } \\
\text { hypertension }\end{array}$}} & \multirow{2}{*}{\multicolumn{2}{|c|}{ Mean }} \\
\hline & & & & & & & & & & & & & & & \\
\hline \multicolumn{2}{|c|}{$\mathbf{M}$} & \multicolumn{2}{|c|}{$\mathbf{F}$} & \multicolumn{2}{|c|}{$\begin{array}{l}6 \text { male } \\
3 \text { female }\end{array}$} & \multicolumn{2}{|c|}{$\mathbf{F}$} & \multicolumn{2}{|r|}{$\mathbf{F}$} & \multicolumn{2}{|c|}{$\mathbf{M}$} & \multicolumn{2}{|r|}{$\mathbf{F}$} & \multicolumn{2}{|c|}{ 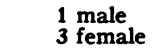 } \\
\hline \multicolumn{2}{|c|}{35} & \multicolumn{2}{|c|}{54} & \multirow{2}{*}{\multicolumn{2}{|c|}{39.3}} & \multicolumn{2}{|c|}{39} & \multicolumn{2}{|r|}{36} & \multicolumn{2}{|c|}{52} & \multicolumn{2}{|r|}{60} & \multicolumn{2}{|c|}{46.8} \\
\hline \multicolumn{2}{|c|}{$\mathbf{T}_{\mathbf{3}}$} & \multicolumn{2}{|c|}{$T_{3}$} & & & \multicolumn{2}{|c|}{$\mathbf{T}_{\mathbf{1}}$} & \multicolumn{2}{|c|}{$T_{1}$} & \multicolumn{2}{|c|}{$T_{3}$} & & $2-T_{4}$ & & \\
\hline C & $\mathbf{E}$ & C & $\mathbf{E}$ & C & $\mathbf{E}$ & C & $\mathbf{E}$ & C & $\mathbf{E}$ & C & $\mathrm{E}$ & C & $\mathbf{E}$ & C & $\mathbf{E}$ \\
\hline 20.1 & 19.2 & 19.2 & 18.4 & 15.9 & 15.7 & 16.4 & 14.6 & 15.4 & 13.6 & 20.2 & 19.0 & 18.1 & 17.1 & 17.5 & 16.1 \\
\hline 12.5 & 10.0 & 12.3 & 10.3 & 9.4 & 8.7 & 9.1 & 6.0 & 9.5 & 6.8 & 11.0 & 5.1 & 11.7 & 9.8 & 10.3 & 6.9 \\
\hline 7.6 & 9.2 & 6.9 & 8.1 & 6.5 & 6.9 & 7.4 & 8.6 & 5.9 & 6.8 & 9.2 & 13.9 & 6.4 & 7.3 & 7.2 & 9.2 \\
\hline 21.2 & 20.4 & 20.5 & 19.7 & 17.1 & 16.8 & 17.6 & 16.0 & 16.4 & 14.6 & & & 19.2 & 18.5 & 17.7 & 16.4 \\
\hline 95 & 94 & 94 & 93 & 93 & 93 & 94 & 91 & 94 & 93 & & & 94 & 93 & 94 & 92 \\
\hline 48.4 & 42.7 & 45.2 & $44.1^{\circ}$ & 43.9 & 43.4 & 38.3 & 36.3 & & & 43.0 & 34.9 & 49.4 & 48.0 & 43.6 & 39.7 \\
\hline 7.41 & 7.43 & & & 7.40 & 7.40 & 7.40 & 7.39 & 7.43 & 7.41 & 7.41 & 7.54 & 7.42 & 7.41 & 7.41 & 7.44 \\
\hline 41 & 35 & & & 37 & 37 & 33 & 31 & & & 37 & 23 & 41 & 40 & 37 & 31 \\
\hline 79 & 79 & 68 & 62 & 78 & 74 & 89 & 79 & 81 & 58 & 84 & 68 & 98 & 102 & 88 & 77 \\
\hline 91 & 69 & 106 & 61 & 92.5 & $63.4 \dagger$ & 124 & 59 & 157 & 110 & 151 & 48 & 199 & 98 & 158 & 79 \\
\hline 37 & 38 & 46 & 41 & 44.6 & 46.1 & 42 & 34 & 46 & 44 & 60 & 32 & 38 & 40 & 46.5 & 37.5 \\
\hline 2.8 & 3.5 & 3.2 & 3.3 & 2.9 & 3.1 & 3.1 & 2.9 & 2.7 & 3.0 & 5.5 & 4.3 & 2.4 & 2.9 & 3.4 & 3.3 \\
\hline 2.5 & 1.8 & 2.3 & 1.5 & 2.1 & $1.5 \dagger$ & 3.0 & 1.7 & 3.4 & 2.5 & 2.5 & 1.5 & 5.2 & 2.5 & 3.5 & 2.1 \\
\hline 5.7 & 5.5 & 6.0 & 3.3 & 4.2 & 3.2 & 2.1 & 3.4 & & & 2.4 & 4.5 & & & & \\
\hline
\end{tabular}

Gm. per minute as compared to $46 \mathrm{ml}$. during high spinal study. Three of the four hypertensive patients showed a decrease in CBF during spinal anesthesia. The double control studies showed a variation in mean values from $45 \mathrm{ml}$. to $43 \mathrm{ml}$. per $100 \mathrm{Gm}$. per minute. When the variation in the mean $\mathrm{CBF}$ in the normotensive high spinal group is compared to the double control variations, the change is not statistically significant.

\section{The cerebral oxygen consumption}

There was no significant change in the mean $\mathrm{CMR} \mathrm{O}_{2}$ in the normotensive patients during high spinal anesthesia as compared to the prespinal value. The small group of hypertensives similarly showed no change in mean $\mathrm{CMR} \mathrm{O}_{2}$ during high spinal anesthesia. The mean $\mathrm{CMR} \mathrm{O}_{2}$ was also unchanged during the double control studies. When the variation in mean $\mathrm{CMR} \mathrm{O}$ values from prespinal to high spinal was compared to those noted in the double control groups, there was no significant difference.

\section{The cerebral vascular resistance}

There was a marked and statistically significant decrease in the mean CVR in the normotensive patients during high spinal anesthesia. The hypertensive patients showed a similar change. In double control studies there was a slight increase from 2.1 to 2.4 units; this change was not significant. The marked decrease in mean CVR in the normotensive patients during high spinal anesthesia was significant when compared to the variation in the double control group. 
JEROME KLEINERMAN, SALVATORE M. SANCETTA, AND DONALD B. HACKEL

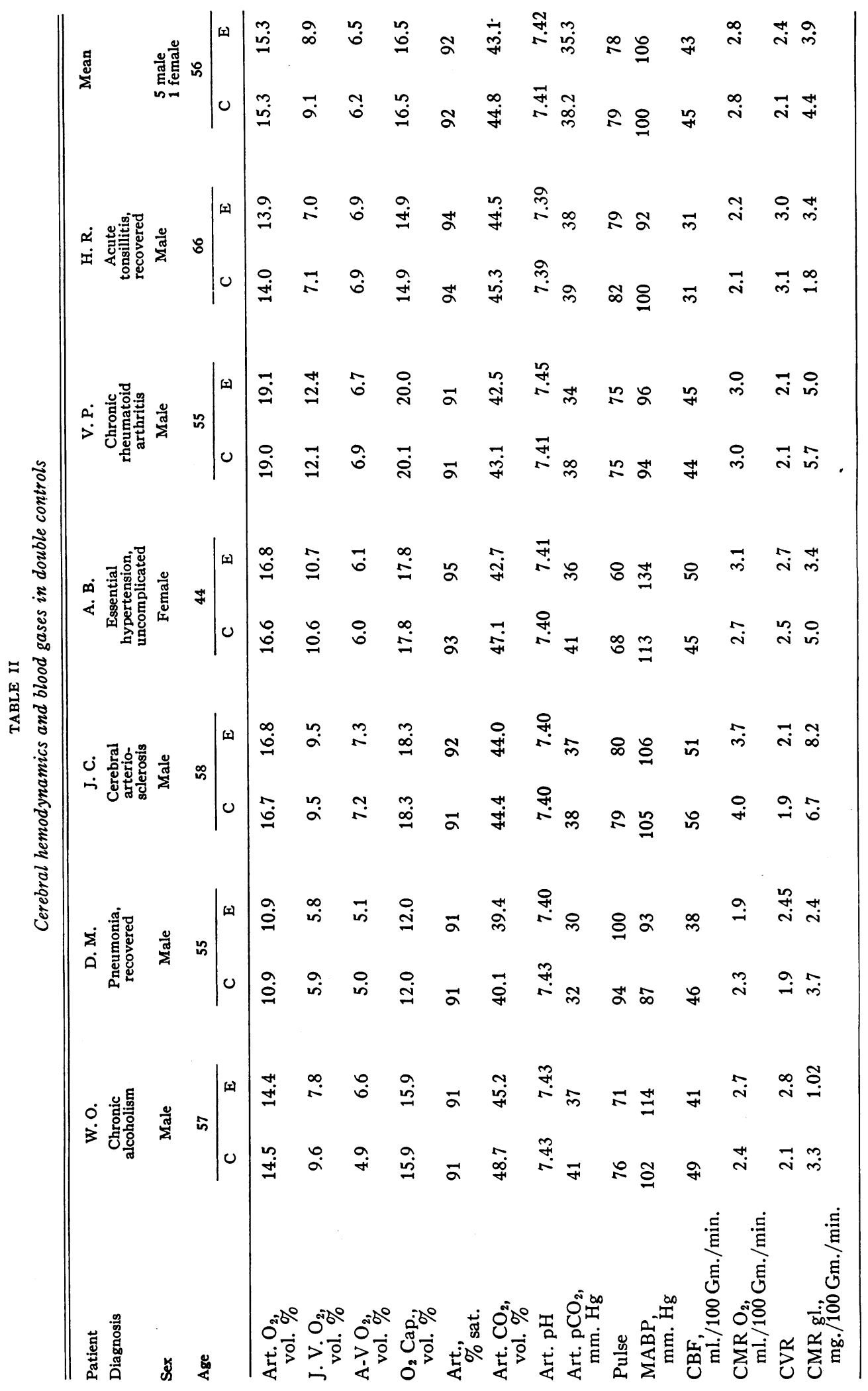


CEREBRAL HEMODYNAMICS IN HIGH SPINAL ANESTHESIA

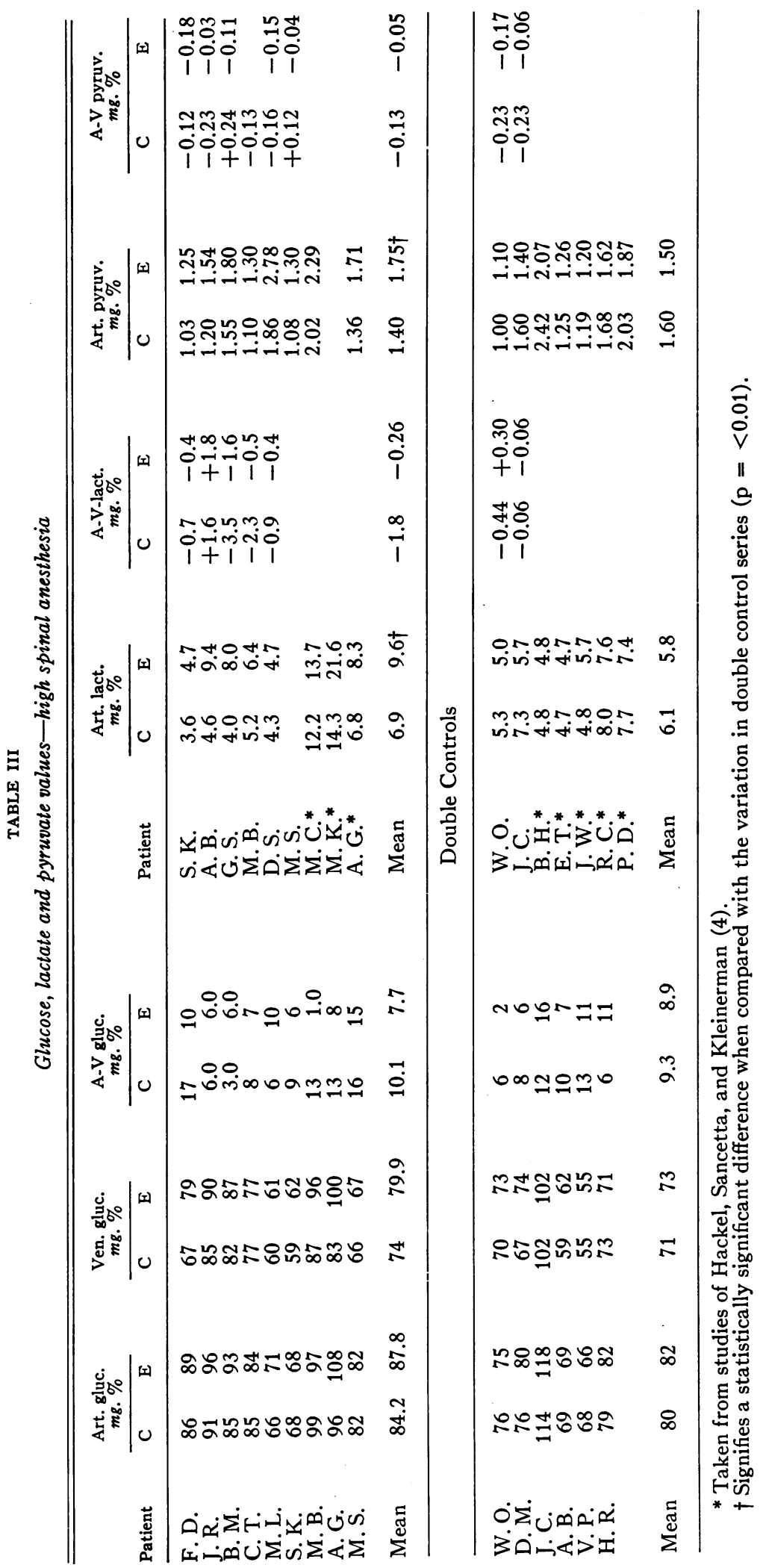




\section{The cerebral glucose consumption}

The mean CMR gl showed no significant change in the normotensive high spinal group, varying from $4.2 \mathrm{mg}$. per $100 \mathrm{Gm}$. per minute in the prespinal study to $3.2 \mathrm{mg}$. per $100 \mathrm{Gm}$. per minute in the spinal period. In the double control group the mean values decreased from $4.4 \mathrm{mg}$. per 100 $\mathrm{Gm}$. per minute in the first study to $3.9 \mathrm{mg}$. per $100 \mathrm{Gm}$. per minute in the second, again a change which was not significant. The values in the hypertensive patients during high spinal anesthesia showed no consistent change. The mean change in CMR gl in the normotensives during high spinal anesthesia was not significantly different from the mean change observed in double control studies.

\section{Blood gases}

In normotensive patients the mean changes in arterial oxygen content, jugular vein oxygen content, arterial-jugular venous oxygen difference, oxygen capacity and arterial oxygen saturation during high spinal anesthesia were not of statistical significance when compared to the prespinal values. This was also true for the mean changes in arterial $\mathrm{CO}_{2}$ content, arterial $\mathrm{pH}$ and arterial $\mathrm{pCO}_{2}$ in the normotensives. The small changes in oxygen and carbon dioxide concentration and in arterial $\mathrm{pH}$ likewise were not significant when compared to the variations observed in the double control group. In the hypertensive group there were more distinct and consistent decreases in the mean arterial oxygen content, jugular vein oxygen content, and oxygen capacity, and a notable increase in the arterial-jugular vein oxygen difference. It is of interest that the decrease in mean oxygen capacity in the hypertensives during high spinal anesthesia paralleled that of the mean arterial oxygen content so that no change in mean arterial oxygen saturation occurred. The mean arterial $\mathrm{CO}_{2}$ content and arterial $\mathrm{pCO}_{2}$ showed small but consistent decreases during high spinal anesthesia as compared to prespinal values. Although the small number of hypertensives studied precluded a statistical analysis, there was a suggestive difference between the normotensive and hypertensive groups in the response of oxygen values and carbon dioxide contents and pressures to spinal anesthesia.

\section{Carbohydrate metabolites}

The mean arterial glucose and venous glucose levels showed slight increases during high spinal anesthesia and similar but smaller increases during the double control studies. The mean arterialjugular vein glucose difference showed a slight decrease in the normotensive spinal group and a similar but smaller decrease in the double control group. The hypertensives behaved similarly in this regard. These changes in the spinal group when analyzed against the double control changes were not statistically significant.

In a small series of five determinations there appeared to be a slight increase in the mean arterial lactate level during high spinal anesthesia. This was not seen in two double control studies. A slight increase was also consistently present in the mean arterial pyruvate level in six high spinal studies, but was seen in only one of two arterial pyruvate studies done in the control series. There were no consistent changes in the mean arterialjugular vein lactate and pyruvate differences of the high spinal and the double control groups. However, the mean arterial-jugular venous lactate difference, although negative, was less negative in four of five observations during high spinal anesthesia. These results are summarized in Table III.

\section{DISCUSSION}

These studies indicate the cerebral vessels in normotensive persons can dilate sufficiently to maintain an entirely adequate cerebral circulation despite the pronounced decrease in mean arterial blood pressure caused by high spinal anesthesia. On the basis of our limited studies in hypertensives, these persons do not appear to have the same capacity for cerebral vascular compensation as do the normotensives. This is in agreement with the results obtained by Kety, King, Horvath, Jeffers, and Hafkenschiel (5) in hypertensives.

The MABP in the normotensive group fell approximately 32 per cent from the control value while the hypertensives decreased to 50 per cent of the control value during the spinal anesthetic studies. During differential spinal block the mean blood pressure drop was 26 per cent in Kety's study. This difference undoubtedly is a reflection of the higher anesthetic level and greater anesthetic 
dosage in the present study (above $\mathrm{T}_{4}$ with evidence of vascular dilatation in the upper extremities). The greatest absolute drop in MABP was obtained in the four hypertensive patients, but the absolute level of the MABP during spinal anesthesia in these hypertensives was no different than the arterial pressure level in the normotensives during spinal anesthesia. The greater decrease in arterial pressure in the four hypertensives as compared to the normotensives is consonant with the known greater reactivity of these patients to spinal anesthesia. Kety and his co-workers pointed to the correlation between the change in mean arterial blood pressure and the change in internal jugular oxygen content as evidence of inadequate cerebral circulatory homeostasis at the greater blood pressure drops. Our limited data in hypertensives corroborate this observation and suggest an inability of the hypertensive patients to obtain complete cerebral circulatory compensation during the severe hypotensive episodes. The arterial-jugular venous oxygen content in the hypertensives showed a consistent increase during the high spinal study, a finding which would be in keeping with a decreased cerebral blood flow if cerebral oxygen consumption is to be maintained.

It is of interest that the arterial lactate and arterial pyruvate levels showed a consistent increase during spinal anesthesia as compared to the prespinal values. Because our observations were numerically inadequate to evaluate these findings, we have combined the present data with those previously reported by our group in another facet of this study (4). This compilation of material is reasonable since all determinations were performed by the same laboratory, using the same technique and methods. Table III indicates that there was a constant and statistically significant increase in the arterial lactate and pyruvate levels during high spinal anesthesia, when compared to the changes observed in the double control group. The arterial glucose and cerebral arteriovenous differences of glucose, lactate, and pyruvate showed no such consistent change.

The mechanism of this increase in arterial lactate and pyruvate is not clear. It seems possible that anoxia of one or several organ systems may be responsible for the lactate and pyruvate changes. Of the systems studied, the heart (4), the splanchnic bed (3), and the kidneys (17) suffer a de- creased blood flow incident to the hypotension of high spinal anesthesia. Evidence has been presented that the hepatosplanchnic oxygen consumption remains unaltered despite a decreased blood flow. The splanchnic bed appears to compensate for the decreased flow by an increased arteriovenous oxygen extraction. The heart, in spite of a decreased oxygen consumption, has a markedly decreased work load and the myocardial oxygen extraction coefficient is not increased. This does not preclude the possible development of an unrecognized oxygen debt. The effects of spinal anesthesia on the renal circulation are more difficult to assess. Recent studies (17) of the effects of high spinal anesthesia in pregnant women point to a decrease in renal plasma flow and an associated increase in renal vascular resistance. No studies of renal oxygen consumption were made. However, earlier studies of spinal anesthesia (18, 19 ), in which the anesthetic level was lower, showed no consistent change in renal blood flow. The critical difference between these results appear to be the effect of the spinal anesthetic on the blood pressure. In the former study, hypotension was produced, whereas the blood pressure level in the latter studies was not affected. It is reasonable to assume that when spinal anesthesia is associated with hypotension, as was the case in our studies, a decrease in renal blood flow can occur, and renal anoxemia may occur. This organ may conceivably be the source of the increased lactate and pyruvate levels during the high spinal studies. It is, of course, possible that temporary ischemia of the liver and splanchnic bed, not discernible by short term physiologic studies, may also contribute.

The mechanism of the decreased cerebrovascular resistance during high spinal anesthesia remains obscure. It is unlikely that there was a direct effect on the cerebral vessels, since the anesthetic level was never above $T_{1}$ and previous studies (20) have shown that bilateral block of the stellate ganglion does not produce a decreased cerebrovascular resistance in normotensive or hypertensive patients. Another mechanism which might decrease the cerebrovascular resistance during high spinal anesthesia is a decrease in the $\mathrm{pCO}_{2}$ or $\mathrm{pH}$ of the cerebral tissues. The jugularvenous blood reflects these changes in the cerebral tissues. We have not gathered sufficient data on 
jugular-venous $\mathrm{pH}$ and $\mathrm{pCO}_{2}$ to implicate this mechanism, but it seems unlikely that metabolic local changes in the cerebral tissues of sufficient degree to alter $\mathrm{pH}$ or $\mathrm{pCO}_{2}$ could occur in the absence of any change in cerebral oxygen uptake, cerebral blood flow, or jugular venous oxygen content. It is possible that local baroreceptors (21) in the carotid arteries and sinus may produce a reflex vasodilation of the cerebral vessels in response to hypotension.

While these results indicate that there is complete circulatory compensation in the brain during the hypotension of high spinal anesthesia in normotensive persons, it must be emphasized that this response is dependent upon local ability to vasodilate and decrease vascular resistance. Foci with vascular sclerosis or other disease may not be able to compensate completely, and may therefore be liable to ischemia. Since the technique employed gives values only for total cerebral circulation and metabolism, small foci of brain receiving a diminished blood flow may not be detected.

\section{CONCLUSIONS}

1. The effects of the hypotension induced by high spinal anesthesia on the cerebral circulation and metabolism of 13 subjects have been studied. Nine of these were normotensive and four were hypertensive. A series of six double control studies served for comparison. In the normotensive group given high spinal anesthesia the MABP fell from a prespinal level of 93 to $63 \mathrm{~mm}$. $\mathrm{Hg}$, but the $\mathrm{CBF}$ did not decrease significantly, and the $\mathrm{CMR} \mathrm{O}_{2}$ was unchanged. The CVR decreased significantly and was responsible for the maintenance of the cerebral blood flow in the face of the 32 per cent decrease in MABP.

In a small group of hypertensive patients, the MABP fell to 50 per cent of the prespinal value during high spinal anesthesia. Suggestive decreases were found in $\mathrm{CBF}$ and $\mathrm{CVR}$ but the CMR $\mathrm{O}_{2}$ did not appear to change in this group.

2. There were no significant changes in the blood gases and $\mathrm{pH}$ in the normotensive group during high spinal anesthesia. The arterial oxygen content, jugular venous oxygen content and oxygen capacity appeared to decrease and the arterial jugular vein oxygen difference to increase in hypertensives during high spinal anesthesia. The arterial $\mathrm{pCO}_{2}$ and arterial $\mathrm{CO}_{2}$ contents showed consistent decreases during spinal anesthesia in the hypertensive patients.

3. The arterial blood lactate and pyruvate were significantly elevated during high spinal anesthesia associated with hypotension. It is suggested that renal or splanchnic ischemia may be responsible for these effects.

\section{ACKNOWLEDGMENT}

The authors wish to express their thanks to Miss Gladys Heckman, Miss Hanna Janouskavec, Mr. Ernest Shiwanov, and Miss Eileen Mikat for technical assistance.

The encouragement and suggestions of Drs. Thomas D. Kinney, F. A. Simeone and R. W. Scott are acknowledged.

\section{REFERENCES}

1. Lynn, R. B., Sancetta, S. M., Simeone, F. A., and Scott, R. W. Observations on the circulation in high spinal anesthesia. Surgery 1952, 32, 195.

2. Sancetta, S. M., Lynn, R. B., Simeone, F. A., and Scott, R. W. Studies of hemodynamic changes in humans following induction of low and high spinal anesthesia. I. General considerations of the problem. Circulation 1952, 6, 559.

3. Mueller, R. P., Lynn, R. B., and Sancetta, S. M. Studies of hemodynamic changes in humans following induction of low and high spinal anesthesia. II. The changes in splanchnic blood flow, oxygen extraction and consumption, and splanchnic vascular resistance in humans not undergoing surgery. Circulation 1952, 6, 894.

4. Hackel, D. B., Sancetta, S. M., and Kleinerman, J. Effect of hypotension due to spinal anesthesia on coronary blood flow and myocardial metabolism. Circulation 1956, 13, 92.

5. Kety, S. S., King, B. D., Horvath, S. M., Jeffers, W. A., and Hafkenschiel, J. H. The effects of an acute reduction in blood pressure by means of differential spinal sympathetic block on the cerebral circulation of hypertensive patients. J. clin. Invest. 1950, 29, 402.

6. Bessman, A. N., Alman, R. W., and Fazekas, J. F. Effect of acute hypotension on cerebral hemodynamics and metabolism of elderly patients. Arch. intern. Med. 1952, 89, 893.

7. Hafkenschiel, J. H., Crumpton, C. W., Moyer, J. H., and Jeffers, W. A. The effects of dihydroergocornine on the cerebral circulation of patients with essential hypertension. J. clin. Invest. 1950, 29, 408.

8. Simeone, F. A., Craney, J. J., Grass, A. M., Linton, R. R., and Lynn, R. B. An oscillographic plethysmograph using a new type of transducer. Science 1952, 116, 355.

9. Hickam, J. B., and Frayser, R. Spectrophotometric 
determination of blood oxygen. J. biol. Chem. 1949, 180, 457.

10. Peters, J. P., and Van Slyke, D. D. Quantitative Clinical Chemistry, Volume II, Methods. Baltimore, Williams and Wilkins, 1932.

11. Rosenthal, T. B. The effect of temperature on the $\mathrm{pH}$ of blood and plasma in vitro. J. biol. Chem. 1948, 173, 25.

12. Singer, R. B., and Hastings, A. B. An improved clinical method for the estimation of disturbances of the acid-base balance of human blood. Medicine 1948, 27, 223.

13. Somogyi, M. Determination of blood sugar. J. biol. Chem. 1945, 160, 69.

14. Barker, S. B., and Summerson, W. H. The colorimetric determination of lactic acid in biological material. J. biol. Chem. 1941, 138, 535.

15. Friedemann, T. E., and Haugen, G. E. Pyruvic acid. II. The determination of keto acids in blood and urine. J. biol. Chem. 1943, 147, 415.

16. Kety, S. S., and Schmidt, C. F. The nitrous oxide method for the quantitative determination of cerebral blood flow in man: Theory, procedure and normal values. J. clin. Invest. 1948, 27, 476.
17. Assali, N. S., Kaplan, S. A., Foman, S. J., Douglass, R. A., and Tada, Y. The effect of high spinal anesthesia on the renal hemodynamics and the excretion of electrolytes during osmotic diuresis in the hydropenic normal pregnant woman. J. clin. Invest. 1951, 30, 916.

18. Smith, H. W., Rovenstine, E. A., Goldring, W., Chasis, H., and Ranges, H. A. The effects of spinal anesthesia on the circulation in normal, unoperated man with reference to autonomy of arterioles, and especially those of the renal circulation. J. clin. Invest. 1939, 18, 319.

19. Mokotoff, R., and Ross, G. The effect of spinal anesthesia on the renal ischemia in congestive heart failure. J. clin. Invest. 1948, 27, 335.

20. Harmel, M. H., Hafkenschiel, J. H., Austin, G. M., Crumpton, C. W., and Kety, S. S. The effect of bilateral stellate ganglion block on the cerebral circulation in normotensive and hypertensive patients. J. clin. Invest. 1949, 28, 415.

21. Green, J. H. Further baroceptor areas associated with the common carotid artery in the cat. J. Physiol. 1954, 123, 41 p. 